\title{
Zipper Assembly of Photoactive Rigid-Rod Naphthalenediimide $\pi$-Stack Architectures on Gold Nanoparticles and Gold Electrodes
}

\author{
Naomi Sakai ${ }^{\dagger}$ Adam L. Sisson, ${ }^{\dagger}$ Thomas Bürgi, ${ }^{\dagger}$ and Stefan Matile*,† \\ ${ }^{\dagger}$ Department of Organic Chemistry, University of Geneva, Geneva, Switzerland and ${ }^{\dagger}$ University of \\ Neuchâtel, Institute of Microtechnology, Neuchâtel, Switzerland. *To whom correspondence should be \\ addressed. E-mail: stefan.matile@chiorg.unige.ch
}

\section{Supporting Information}

Table of Content

1. Materials and methods $\quad$ S2

2. Supplementary text S4

2.1 Synthesis of the anionic initiator $1 \quad$ S4

$\begin{array}{lll}2.2 & \text { Synthesis of the cationic propagator } 2 & \text { S11 }\end{array}$

2.3 Synthesis of the anionic propagator $3 \quad$ S11

$\begin{array}{lll}2.4 & \text { Electrochemistry } & \mathrm{S} 12\end{array}$

2.5 Zipper assembly on gold nanoparticles (Au-nps) S13

$\begin{array}{lll}2.6 & \text { Zipper assembly on gold electrodes } & \text { S15 }\end{array}$

$\begin{array}{ll}3 . & \text { Supplementary schemes and figures }\end{array}$

4. Supplementary tables $\quad$ S25

$\begin{array}{lll}\text { 5. Supplementary references } & \text { S26 }\end{array}$ 


\section{Materials and methods}

As in ref. S1, Supplementary Information. Briefly, reagents for synthesis were purchased from Fluka, amino acid derivatives from Novabiochem and Bachem, HATU from Applied Biosystems, buffers, and salts from Sigma or Fluka-Aldrich. All reactions were performed under $\mathrm{N}_{2}$ or argon atmosphere. Unless stated otherwise, column chromatography was carried out on silica gel 60 (Fluka, 40-63 $\mu \mathrm{m}$ ). Analytical (TLC) and preparative thin layer chromatography (PTLC) were performed in silica gel 60 (Fluka, $0.2 \mathrm{~mm}$ ) and silica gel GF (Analtech, $1000 \mu \mathrm{m}$ ), respectively. HPLC was performed using either Jasco HPLC system (PU-980, UV-970, FP-920) or an Agilent 1100 series apparatus with a photo diode array detector. $[\alpha]^{20}$ values were recorded on a Jasco P1030 Polarimeter, melting points (m.p.) on a heating table from Reichert (Austria), IR spectra were recorded on a Perkin Elmer Spectrum One FT-IR spectrometer (ATR, Golden Gate, unless stated) and are reported as wavenumbers $v$ in $\mathrm{cm}^{-1}$ with band intensities indicated as s (strong), $\mathrm{m}$ (medium), w (weak). ESI-MS were performed on a Finnigan MAT SSQ 7000 instrument or a ESI API 150EX, HR ESI-MS on a Sciex QSTAR Pulsar mass spectrometer, MALDI-TOF on a Axima CFR ${ }^{+}$ (Shimadzu). ${ }^{1} \mathrm{H}$ and ${ }^{13} \mathrm{C}$ spectra were recorded (as indicated) either on a Bruker $300 \mathrm{MHz}, 400$ $\mathrm{MHz}$ or $500 \mathrm{MHz}$ spectrometer and are reported as chemical shifts $(\delta)$ in ppm relative to TMS $(\delta=$ 0). Spin multiplicities are reported as a singlet (s), doublet (d), triplet (t), quartet (q) and quintet (quint) with coupling constants $(J)$ given in $\mathrm{Hz}$, or multiplet $(\mathrm{m})$. Broad peaks are marked as br. ${ }^{1} \mathrm{H}$ and ${ }^{13} \mathrm{C}$ resonances were assigned with the aid of additional information from 1D \& 2D NMR spectra (H,H-COSY, DEPT 135, HSQC and HMBC). UV-Vis spectra were measured on a Varian Cary 1 Bio spectrophotometer and are reported as maximal absorption wavelength $\lambda$ in $\mathrm{nm}$ 
(extinction coefficient $\varepsilon$ in $\mathrm{mM}^{-1} \mathrm{~cm}^{-1}$ ). Electrochemical measurements were done on an Electrochemical Analyzer with Picoamp booster and Faraday cage (CH Instruments 660C). Eppendorf Minispin centrifuge was used for the precipitation of gold nanoparticles. Photocurrents measurements were performed using a $150 \mathrm{~W}$ Xe lamp (Hamamatsu), or a $150 \mathrm{~W}$ solar simulator (Oriel, with AM 1.5 filter), and analyzed with an Electrochemical Analyzer (CH Instruments 660C). The power of light was measured using a portable laser power meter (Spectra Physics Model 407A) or a radiant power meter (Newport model 70260 for solar simulator).

Abbreviations. ACN: acetonitrile; Alloc: Allyloxycarbonyl; Au-nps: gold nanoparticles; Boc: $t$ Butoxycarbonyl; calcd: Calculated; CS: charge-separated; DMA: N,N-Dimethylaniline; DMF: N,N-Dimethylformamide; en: Ethylenediamine; Fc: Ferrocene; Gla: Glycolic acid; Glu: L-Glutamic acid; HATU: N-[(Dimethylamino)-1H-1,2,3 -triazolo[4,5-b]pyridin-1-ylmethylene]-Nmethylmethanammonium hexafluorophosphate N-oxide; HRMS: High resolution mass spectrometry; Lys: L-Lysine; NDI: Naphthalenediimide;, RPHPLC: Reverse phase high performance liquid chromatography; rt: Room temperature; sh: Shoulder; SPR: Surface plasmon resonance; TEA: Triethylamine; TEOA: Triethanolamine; TFA: Trifluoroacetic acid; TFE: 2,2,2Trifluoroethanol; Z: (Benzyloxy)carbonyl. 


\section{Supplementary text}

\subsection{Synthesis of the anionic initiator 1}

3-(2-Z-Aminoethoxy)-phenol 6. A suspension of resorcinol $(\mathbf{5}, 1.7 \mathrm{~g}, 15 \mathrm{mmol})$, cesium carbonate $(2.3 \mathrm{~g}, 7.1 \mathrm{mmol})$, and Z-bromoethyleneamine $(7,1.6 \mathrm{~g}, 6.2 \mathrm{mmol})^{\mathrm{S} 2}$ in DMF (5 ml) was stirred for $18.5 \mathrm{~h}$ at $40{ }^{\circ} \mathrm{C}$. The mixture was acidified with $1 \mathrm{M} \mathrm{HCl}$, and extracted with EtOAc (three times). The combined organic phase was washed with brine, dried over $\mathrm{Na}_{2} \mathrm{SO}_{4}$ and concentrated in vacuo. Silica gel column chromatography $\left(\mathrm{CH}_{2} \mathrm{Cl}_{2} / \mathrm{MeOH}=20 / 1\right)$ of the residue afforded pure 6 as a colorless solid $(1.0 \mathrm{~g}, 56 \%)$. MP: 111-112 ${ }^{\circ} \mathrm{C}$; IR: $v 3356(\mathrm{~m}), 3224(\mathrm{~m}), 2951$ (w), 1673 (s), 1628 (m), 1605 (m), 1587 (m), 1538 (s), 1493 (s), 1457 (s), 1340 (m), 1294 (m), 1266 (s), $1241(\mathrm{~s}), 1146(\mathrm{~s}), 1111(\mathrm{~m}), 1065(\mathrm{~m}), 1023(\mathrm{~m}), 973(\mathrm{~m}), 854(\mathrm{~m}), 846(\mathrm{~m}), 761(\mathrm{~s}), 697(\mathrm{~s})$ 684 (s), 654 (s), 607 (s); ${ }^{1} \mathrm{H}$ NMR (400 MHz, $\left.\mathrm{CDCl}_{3}\right): \delta 7.36(\mathrm{~s}, 5 \mathrm{H}), 7.12\left(\mathrm{t},{ }^{3} J(\mathrm{H}, \mathrm{H})=8.3 \mathrm{~Hz}\right.$ 1H), $6.45(\mathrm{~m}, 2 \mathrm{H}), 6.40(\mathrm{~s}, 1 \mathrm{H}), 5.24(\mathrm{brs}, 1 \mathrm{H}), 5.12(\mathrm{~s}, 2 \mathrm{H}), 4.02\left(\mathrm{t},{ }^{3} J(\mathrm{H}, \mathrm{H})=5.0 \mathrm{~Hz}, 2 \mathrm{H}\right), 3.60$ (m, 2H); MS (ESI, +ve): $m / z(\%) 305.4\left(93\left[\mathrm{M}+\mathrm{NH}_{4}\right]^{+}\right), 288.3\left(85[\mathrm{M}+\mathrm{H}]^{+}\right), 244.4(100[\mathrm{M}+\mathrm{H}$ $\left.-\mathrm{CO}_{2}\right]^{+}$.

2-Iodo-5-(2-Z-aminoethoxy)-phenol 8. To a suspension of 6 (1.28 g, $4.5 \mathrm{mmol})$, and silver triflate $(0.99 \mathrm{~g}, 4.5 \mathrm{mmol})$ in $\mathrm{CHCl}_{3}(10 \mathrm{ml})$ was added a solution of iodine $(1.13 \mathrm{~g}, 4.5 \mathrm{mmol})$ in $\mathrm{CHCl}_{3}(40 \mathrm{ml})$ over $1.5 \mathrm{~h}$ at rt. ${ }^{\mathrm{S} 3}$ The mixture was stirred for $2 \mathrm{~h}$ at $\mathrm{rt}$, and filtered. The filtrate was washed successively with $5 \%$ aqueous $\mathrm{Na}_{2} \mathrm{~S}_{2} \mathrm{O}_{5}, 5 \%$ aqueous $\mathrm{NaHCO}_{3}$, and water, dried over $\mathrm{Na}_{2} \mathrm{SO}_{4}$ and concentrated in vacuo. The residue was chromatographed on silica gel $\left(\mathrm{CH}_{2} \mathrm{Cl}_{2} / \mathrm{MeOH}\right.$ $=40 / 1)$ to give $\mathbf{8}$ as a colorless solid (0.86 g, $47 \%$, c. y., quant) together with recovered starting 
material 6 (0.7 g). MP: 76 - $78^{\circ} \mathrm{C}$; IR: v 3413 (w), 3233 (m), 2941 (w), $1679(\mathrm{~m}), 1656$ (s), 1586 (m), 1555 (s), 1505 (m), 1430 (m), 1357 (m), 1282 (s), 1259 (s), 1214 (s), 1180 (s), 1156 (s), 1109 (m), 1067 (m), 1036 (m), 983 (m), 905 (m), 840 (m), 778 (m), 745 (m), 693 (s), 628 (s); ${ }^{1} \mathrm{H}$ NMR $\left(400 \mathrm{MHz}, \mathrm{CDCl}_{3}\right): \delta 7.49\left(\mathrm{~d},{ }^{3} J(\mathrm{H}, \mathrm{H})=8.8 \mathrm{~Hz}, 1 \mathrm{H}\right), 7.36(\mathrm{~m}, 5 \mathrm{H}), 6.57\left(\mathrm{~d},{ }^{4} J(\mathrm{H}, \mathrm{H})=2.5 \mathrm{~Hz}\right.$, $1 \mathrm{H}), 6.30\left(\mathrm{dd},{ }^{3} J(\mathrm{H}, \mathrm{H})=8.8 \mathrm{~Hz},{ }^{4} J(\mathrm{H}, \mathrm{H})=2.5 \mathrm{~Hz}, 1 \mathrm{H}\right), 5.60$ (brs, $\left.1 \mathrm{H}\right), 5.23$ (brs, 1H), $5.12(\mathrm{~s}$, $2 \mathrm{H}), 4.00\left(\mathrm{t},{ }^{3} J(\mathrm{H}, \mathrm{H})=5.1 \mathrm{~Hz}, 2 \mathrm{H}\right), 3.59\left(\mathrm{brq},{ }^{3} J(\mathrm{H}, \mathrm{H})=5.3 \mathrm{~Hz}, 2 \mathrm{H}\right) ;{ }^{13} \mathrm{C}$ NMR $(100 \mathrm{MHz}$, $\left.\mathrm{CDCl}_{3}\right): \delta 160.7$ (s), 156.7 (s), 156.0 (s), $138.4(\mathrm{~d}), 136.5$ (s), 128.8 (d), 128.5 (d), 128.4 (d) 109.8 (d), 101.7 (d), $75.1(\mathrm{~s}), 67.3(\mathrm{t}), 40.6(\mathrm{t}) ; \mathrm{MS}(\mathrm{ESI},+\mathrm{ve}): \mathrm{m} / \mathrm{z}(\%) 431.3\left(88\left[\mathrm{M}+\mathrm{NH}_{4}\right]^{+}\right), 414.1(67$ $\left.[\mathrm{M}+\mathrm{H}]^{+}\right), 370.1\left(100\left[\mathrm{M}+\mathrm{H}-\mathrm{CO}_{2}\right]^{+}\right)$.

tert-Butyl [2-iodo-5-(2-Z-aminoethoxy)-phenoxy]-acetate 9. To a suspension of phenol 8 $(0.20 \mathrm{~g}, 0.48 \mathrm{mmol})$ and cesium carbonate $(0.24 \mathrm{~g}, 0.74 \mathrm{mmol})$ in DMF $(1 \mathrm{ml})$ was added tert-butyl bromoacetate $(90 \mu \mathrm{l}, 0.61 \mathrm{mmol})$. The mixture was stirred for $15 \mathrm{~min}$ at $90{ }^{\circ} \mathrm{C}$, and then allowed to cool down to rt. The product was extracted by EtOAc against water, dried over $\mathrm{Na}_{2} \mathrm{SO}_{4}$, and concentrated in vacuo. Silica gel column chromatography of the residue (petroleum ether / EtOAc 4 / 1) afforded pure $9(0.21 \mathrm{~g}, 83 \%)$ as a colorless solid. MP: $54-55^{\circ} \mathrm{C}$; IR: $v 3300(\mathrm{~m}), 2935(\mathrm{w})$, 2888 (w), 1750 (s), 1719 (m), 1692 (s), 1590 (m), 1577 (m), 1551 (s), 1426 (m), 1304 (m), 1281 (m), 1257 (s), 1234 (s), 1194 (s), 1152 (s), 1134 (s), 1069 (s), 1053 (s), 846 (s), 748 (s), 699 (s), 626 (s); ${ }^{1} \mathrm{H}$ NMR $\left(400 \mathrm{MHz}, \mathrm{CDCl}_{3}\right): \delta 7.62\left(\mathrm{~d},{ }^{3} J(\mathrm{H}, \mathrm{H})=8.3 \mathrm{~Hz}, 1 \mathrm{H}\right), 7.36(\mathrm{~m}, 5 \mathrm{H}), 6.33 \sim 6.30(\mathrm{~m}$, 2H), 5.23 (brs, 1H), $5.12(\mathrm{~s}, 2 \mathrm{H}), 4.54(\mathrm{~s}, 2 \mathrm{H}), 3.99\left(\mathrm{t},{ }^{3} \mathrm{~J}(\mathrm{H}, \mathrm{H})=5.0 \mathrm{~Hz}, 2 \mathrm{H}\right), 3.58\left(\mathrm{brq},{ }^{3} J(\mathrm{H}, \mathrm{H})=\right.$ $5.0 \mathrm{~Hz}, 2 \mathrm{H}), 1.49$ (s, 9H); ${ }^{13} \mathrm{C} \mathrm{NMR}\left(100 \mathrm{MHz}, \mathrm{CDCl}_{3}\right): \delta 161.4(\mathrm{~s}), 160.2(\mathrm{~s}), 157.7$ (s), 156.6 (s), 139.8 (d), 136.5 (s), 128.8 (d), 128.5 (d), 128.4 (d) 108.8 (d), 100.8 (d), 82.9 (s), 75.9 (s), 67.4 (t), 
$67.2(\mathrm{t}), 66.8(\mathrm{t}), 40.7(\mathrm{t}), 28.3(\mathrm{q}) ; \mathrm{MS}(\mathrm{ESI},+\mathrm{ve}): \mathrm{m} / z(\%) 545.3\left(97\left[\mathrm{M}+\mathrm{NH}_{4}\right]^{+}\right), 528.3(24[\mathrm{M}$ $\left.+\mathrm{H}]^{+}\right), 472.3\left(83[\mathrm{M}+\mathrm{H}-\mathrm{Bu}]^{+}\right), 428.3\left(97\left[\mathrm{M}+\mathrm{H}-\mathrm{CO}_{2} \mathrm{Bu}\right]^{+}\right), 345.5\left(90[\mathrm{M}+\mathrm{H}-\mathrm{I}-\mathrm{Bu}]^{+}\right)$, $258.3\left(100\left[\mathrm{M}+\mathrm{H}-\mathrm{CO}_{2} \mathrm{Bu}-\mathrm{I}-\mathrm{CO}_{2}\right]^{+}\right)$.

\section{tert-Butyl [5-(2-Z-aminoethoxy)-2-(4,4,5,5-tetramethyl-[1,3,2]dioxaborolan-2-yl)-}

phenoxy]-acetate 10. To a degassed solution of $9(300 \mathrm{mg}, 0.57 \mathrm{mmol})$ in acetonitrile $(6 \mathrm{ml})$, $\mathrm{PdCl}_{2}(\mathrm{dppf})(8 \mathrm{mg}, 0.01 \mathrm{mmol})$, pinacolborane $(160 \mu \mathrm{l}, 1.11 \mathrm{mmol})$, and TEA $(0.32 \mathrm{ml}, 2.3 \mathrm{mmol})$ were successively added. ${ }^{\mathrm{S} 4}$ The resulting mixture was heated at $90{ }^{\circ} \mathrm{C}$ for $1 \mathrm{~h}$. The mixture was concentrated in vacuo, and the residue was purified by column chromatography (petroleum ether / EtOAc $2 / 1)$ to give pure boronate 10 as pale yellow oil $(0.26 \mathrm{~g}, 87 \%)$. Oil; IR: $v 2980(\mathrm{~m}), 1749$ (m), 1720 (s), 1604 (s), 1512 (m), 1422 (m), 1370 (m), 1350 (s), 1248 (s), 1227 (s), 1143 (s), 1084 (s), 732 (s), 699 (s); ${ }^{1} \mathrm{H}$ NMR (400 MHz, $\left.\mathrm{CDCl}_{3}\right): \delta 7.63\left(\mathrm{~d},{ }^{3} J(\mathrm{H}, \mathrm{H})=8.1 \mathrm{~Hz}, 1 \mathrm{H}\right), 7.36(\mathrm{~m}, 5 \mathrm{H})$, $6.49\left(\mathrm{brd},{ }^{3} J(\mathrm{H}, \mathrm{H})=8.1 \mathrm{~Hz}, 1 \mathrm{H}\right), 6.32\left(\mathrm{~d},{ }^{4} J(\mathrm{H}, \mathrm{H})=1.8 \mathrm{~Hz}, 1 \mathrm{H}\right), 5.30(\mathrm{brs}, 1 \mathrm{H}), 5.11(\mathrm{~s}, 2 \mathrm{H})$, $4.51(\mathrm{~s}, 2 \mathrm{H}), 4.02\left(\mathrm{t},{ }^{3} J(\mathrm{H}, \mathrm{H})=5.0 \mathrm{~Hz}, 2 \mathrm{H}\right), 3.58\left(\mathrm{brq},{ }^{3} J(\mathrm{H}, \mathrm{H})=5.0 \mathrm{~Hz}, 2 \mathrm{H}\right), 1.48(\mathrm{~s}, 9 \mathrm{H}), 1.34$ (s, 12H); ${ }^{13} \mathrm{C}$ NMR (100 MHz, $\left.\mathrm{CDCl}_{3}\right): \delta 168.3$ (s), 164.7 (s), 162.4 (s), 156.6 (s), 138.6 (d), 136.6 (s), 128.8 (d), $128.4(\mathrm{~d}), 128.3$ (d), 111.5 (s), 106.8 (d), 100.8 (d), $83.5(\mathrm{~s}), 82.2(\mathrm{~s}), 67.5$ (t), 67.1 $(\mathrm{t}), 67.0(\mathrm{t}), 40.7(\mathrm{t}), 28.3(\mathrm{q}), 25.1(\mathrm{q}) ; \mathrm{MS}(\mathrm{ESI},+\mathrm{ve}): \mathrm{m} / z(\%) 545.5\left(100\left[\mathrm{M}+\mathrm{NH}_{4}\right]^{+}\right), 528.5(8$ $\left.[\mathrm{M}+\mathrm{H}]^{+}\right), 472.3\left(88[\mathrm{M}+\mathrm{H}-\mathrm{Bu}]^{+}\right), 428.5\left(38\left[\mathrm{M}+\mathrm{H}-\mathrm{CO}_{2} \mathrm{Bu}\right]^{+}\right), 372.5(52[\mathrm{M}+\mathrm{H}-\mathrm{Bu}-$ $\left.\left.\mathrm{C}_{6} \mathrm{H}_{12} \mathrm{O}\right]^{+}\right), 328.5\left(62\left[\mathrm{M}+\mathrm{H}-\mathrm{CO}_{2} \mathrm{Bu}-\mathrm{C}_{6} \mathrm{H}_{12} \mathrm{O}\right]^{+}\right)$.

$1^{4}$-Iodo-1 ${ }^{3}, 2^{3}, 3^{2}$-tri(Gla-O-t-Bu)-p-terphenyl 11. Terphenyl 11 was obtained in four steps from commercially available Fast Blue-B as reported in ref. S5. 
$1^{4}$-(2-Z-aminoethoxy)-1 $1^{2}, 2^{2}, 3^{3}, 4^{2}$-tetra(Gla-Ot-Bu)-p-quaterphenyl 12. To a degassed solution of mono-iodo $p$-terphenyl $(\mathbf{1 1}, 160 \mathrm{mg}, 0.21 \mathrm{mmol})$ in toluene $(8 \mathrm{ml}), 2 \mathrm{M} \mathrm{Na}_{2} \mathrm{CO}_{3}$ aqueous solution ( $2 \mathrm{ml}), \mathrm{PdCl}_{2}(\mathrm{dppf})(18 \mathrm{mg}, 0.022 \mathrm{mmol})$ and a solution of boronate $\mathbf{1 0}$ (200 $\mathrm{mg}, 0.38$ mmol) in EtOH ( $2 \mathrm{ml})$ were successively added. The mixture was stirred for $1 \mathrm{~h}$ at $90{ }^{\circ} \mathrm{C}$ then another portion of boronate $\mathbf{1 0}(100 \mathrm{mg}, 0.19 \mathrm{mmol})$ in $\mathrm{EtOH}(1 \mathrm{ml})$ was added. After 1 more hour, the mixture was allowed to cool down to rt. The product was extracted by EtOAc, dried over $\mathrm{Na}_{2} \mathrm{SO}_{4}$ and concentrated in vacuo. Column chromatography of the residue (petroleum ether / EtOAc 2 / 1; $\mathrm{CH}_{2} \mathrm{Cl}_{2}$ / acetone 100 / 1.5; then again petroleum ether / EtOAc 2 / 1) provided pure $p$ quaterphenyl 12 as a colorless solid (173 mg, $79 \%)$. MP: $132-133{ }^{\circ} \mathrm{C} ;{ }^{1} \mathrm{H}$ NMR $(400 \mathrm{MHz}$, $\left.\mathrm{CDCl}_{3}\right): \delta 7.47\left(\mathrm{~d},{ }^{3} J(\mathrm{H}, \mathrm{H})=8.0 \mathrm{~Hz}, 1 \mathrm{H}\right), 7.44\left(\mathrm{~d},{ }^{3} J(\mathrm{H}, \mathrm{H})=8.1 \mathrm{~Hz}, 2 \mathrm{H}\right), 7.39 \sim 7.32(\mathrm{~m}, 7 \mathrm{H})$, $7.30 \sim 7.26(\mathrm{~m}, 2 \mathrm{H}), 7.10 \sim 7.06(\mathrm{~m}, 3 \mathrm{H}), 6.88\left(\mathrm{~d},{ }^{3} J(\mathrm{H}, \mathrm{H})=8.3 \mathrm{~Hz}, 1 \mathrm{H}\right), 6.60\left(\mathrm{dd},{ }^{4} J(\mathrm{H}, \mathrm{H})=2.0\right.$ $\left.\mathrm{Hz},{ }^{3} J(\mathrm{H}, \mathrm{H})=8.3 \mathrm{~Hz}, 1 \mathrm{H}\right), 6.45\left(\mathrm{~d},{ }^{4} J(\mathrm{H}, \mathrm{H})=2.0 \mathrm{~Hz}, 1 \mathrm{H}\right), 5.29(\mathrm{brs}, 1 \mathrm{H}), 5.14(\mathrm{~s}, 2 \mathrm{H}), 4.54(\mathrm{~s}$, $4 \mathrm{H}), 4.53(\mathrm{~s}, 2 \mathrm{H}), 4.50(\mathrm{~s}, 2 \mathrm{H}), 4.08\left(\mathrm{t},{ }^{3} J(\mathrm{H}, \mathrm{H})=4.8 \mathrm{~Hz}, 2 \mathrm{H}\right), 3.63\left(\mathrm{brq},{ }^{3} J(\mathrm{H}, \mathrm{H})=5.0 \mathrm{~Hz}, 2 \mathrm{H}\right)$, $1.48(\mathrm{~s}, 9 \mathrm{H}), 1.47(\mathrm{~s}, 27 \mathrm{H}) ; \mathrm{MS}(\mathrm{ESI},+\mathrm{ve}): \mathrm{m} / z(\%) 1042.6\left(40[\mathrm{M}+\mathrm{Na}]^{+}\right), 1037.7(100[\mathrm{M}+$ $\left.\left.\mathrm{NH}_{4}\right]^{+}\right), 796.5\left(72[\mathrm{M}+\mathrm{H}-4 \mathrm{Bu}]^{+}\right), 752.5\left(90\left[\mathrm{M}+\mathrm{H}-4 \mathrm{Bu}-\mathrm{CO}_{2}\right]^{+}\right)$.

\section{$1^{4}$-(2- Lipoylaminoethoxy)-1 $1^{2}, 2^{2}, 3^{3}, 4^{2}$-tetra(Gla-Ot-Bu)-p-quaterphenyl 13. A suspension} of tetramer $12(29 \mathrm{mg}, 28 \mu \mathrm{mol})$ and $\mathrm{Pd}-\mathrm{C}(10 \%, 10 \mathrm{mg})$ in EtOAc $(3 \mathrm{ml})$ and $\mathrm{MeOH}(1 \mathrm{ml})$ was stirred for 1 day under hydrogen atmosphere. The mixture was filtered through a pad of celite and concentrated in vacuo. The residue was purified by PTLC $\left(\mathrm{CH}_{2} \mathrm{Cl}_{2} / \mathrm{MeOH} 4 / 1\right)$ to give a pure amine (20 mg, $79 \%$ ). The obtained amine (20 mg, $0.023 \mathrm{mmol}$ ) was dissolved in DMF (0.5 mg), 
and lipoic acid (6 mg, $0.029 \mathrm{mmol})$, HATU (10 mg, $0.026 \mathrm{mmol})$ and TEA (10 $\mu 1,0.072 \mathrm{mmol})$ were successively added to it. After 10 min of stirring, the mixture was concentrated and the residue was purified by PTLC $\left(\mathrm{CH}_{2} \mathrm{Cl}_{2}\right.$ / acetone $\left.9: 1\right)$ to give pure 13 as colorless oil (20 mg, $\left.82 \%\right)$. Oil; ${ }^{1} \mathrm{H}$ NMR (300 MHz, $\left.\mathrm{CDCl}_{3}\right): \delta 7.51 \sim 7.45(\mathrm{~m}, 3 \mathrm{H}), 7.40\left(\mathrm{~d},{ }^{3} J(\mathrm{H}, \mathrm{H})=8.4 \mathrm{~Hz}, 1 \mathrm{H}\right), 7.36(\mathrm{~m}, 1 \mathrm{H})$, $7.32 \sim 7.27(\mathrm{~m}, 2 \mathrm{H}), 7.14 \sim 7.08(\mathrm{~m}, 3 \mathrm{H}), 6.91\left(\mathrm{~d},{ }^{3} J(\mathrm{H}, \mathrm{H})=8.2 \mathrm{~Hz}, 1 \mathrm{H}\right), 6.64\left(\mathrm{dd},{ }^{3} J(\mathrm{H}, \mathrm{H})=8.5\right.$ $\left.\mathrm{Hz},{ }^{4} J(\mathrm{H}, \mathrm{H})=2.3 \mathrm{~Hz}, 1 \mathrm{H}\right), 6.50\left(\mathrm{~d},{ }^{4} J(\mathrm{H}, \mathrm{H})=2.3 \mathrm{~Hz}, 1 \mathrm{H}\right), 6.00\left(\mathrm{brt},{ }^{3} J(\mathrm{H}, \mathrm{H})=5.4 \mathrm{~Hz}, 1 \mathrm{H}\right)$, $4.58(\mathrm{~s}, 2 \mathrm{H}), 4.57(\mathrm{~s}, 2 \mathrm{H}), 4.56(\mathrm{~s}, 2 \mathrm{H}), 4.54(\mathrm{~s}, 2 \mathrm{H}), 4.11\left(\mathrm{t},{ }^{3} \mathrm{~J}(\mathrm{H}, \mathrm{H})=4.8 \mathrm{~Hz}, 2 \mathrm{H}\right), 3.73\left(\mathrm{dt},{ }^{3} J\right.$ $(\mathrm{H}, \mathrm{H})=5.4 \mathrm{~Hz}, 4.8 \mathrm{~Hz}, 2 \mathrm{H}), 3.61(\mathrm{~m}, 1 \mathrm{H}), 3.26 \sim 3.10(\mathrm{~m}, 2 \mathrm{H}), 2.49(\mathrm{~m}, 1 \mathrm{H}), 2.28\left(\mathrm{t},{ }^{3} J(\mathrm{H}, \mathrm{H})=\right.$ $7.3 \mathrm{~Hz}, 2 \mathrm{H}), 1.96(\mathrm{~m}, 1 \mathrm{H}), 1.80 \sim 1.40(\mathrm{~m}, 6 \mathrm{H}), 1.51(\mathrm{~s}, 18 \mathrm{H}), 1.50(\mathrm{~s}, 18 \mathrm{H}) ;{ }^{13} \mathrm{C} \mathrm{NMR}(100 \mathrm{MHz}$, $\left.\mathrm{CDCl}_{3}\right): \delta 173.1(\mathrm{~s}), 168.5(\mathrm{~s}), 168.3(\mathrm{~s}), 168.3(\mathrm{~s}), 159.2(\mathrm{~s}), 156.7(\mathrm{~s}), 155.9(\mathrm{~s}), 155.8(\mathrm{~s}), 141.7$ (s), 141.5 (s), 132.8 (d), 132.6 (d), 132.5 (s), 132.3 (d), 128.8 (d), 127.6 (s), 127.1 (s), 126.7 (s), 121.5 (d), 120.7 (s), 120.4 (d), 112.6(d), 111.7(d), 111.6 (d), 106.4 (d), 100.6 (d), 82.2 (s), 67.1 (t), $66.8(\mathrm{t}), 66.8(\mathrm{t}), 66.6(\mathrm{t}), 56.6(\mathrm{~d}), 40.4(\mathrm{t}), 39.1(\mathrm{t}), 38.7(\mathrm{t}), 36.7(\mathrm{t}), 34.9(\mathrm{t}), 29.1(\mathrm{t}), 28.3(\mathrm{q})$, $25.6(\mathrm{t}) ; \mathrm{MS}(\mathrm{ESI},+\mathrm{ve}): \mathrm{m} / z(\%) 1097.1\left(32[\mathrm{M}+\mathrm{Na}]^{+}\right), 1091.8\left(90\left[\mathrm{M}+\mathrm{NH}_{4}\right]^{+}\right), 1074.8(23[\mathrm{M}$ $\left.+\mathrm{H}]^{+}\right), 1018.5\left(22[\mathrm{M}+\mathrm{H}-\mathrm{Bu}]^{+}\right), 962.5\left(23[\mathrm{M}+\mathrm{H}-2 \mathrm{Bu}]^{+}\right), 906.5\left(30[\mathrm{M}+\mathrm{H}-3 \mathrm{Bu}]^{+}\right), 850.5$ $\left(100[\mathrm{M}+\mathrm{H}-4 \mathrm{Bu}]^{+}\right)$.

2,6-Dichloronaphthalene-1,4,5,8-tetracarboxylic acid dianhydride 14. This compound was prepared in four steps from pyrene following the reported procedures. ${ }^{\mathrm{S} 6}$

Alloc-en-[Cl,Cl]-NDI-Glu(tert-Bu)-NH $\mathbf{N H}_{2}$ 15. A solution of alloc-ethylenediamine (263 mg, 1.31 mmol $)^{\mathrm{S} 1}$ and $\mathrm{H}-\mathrm{Glu}($ tert $-\mathrm{Bu})-\mathrm{NH}_{2}(188 \mathrm{mg}, 1.31 \mathrm{mmol})$ in acetic acid $(7 \mathrm{ml})$ was added to $\mathbf{1 4}(220$ 
$\mathrm{mg}, 0.653 \mathrm{mmol}$ ). The resultant suspension was stirred at $90{ }^{\circ} \mathrm{C}$ for $20 \mathrm{~h}$, after which time the reaction mixture became a brown solution. This solution was diluted with EtOAc $(150 \mathrm{ml})$, washed succesively with $1 \mathrm{M} \mathrm{KHSO} 4(2 \times 50 \mathrm{ml})$, water $(50 \mathrm{ml})$ and brine $(50 \mathrm{ml})$, The organic phase was dried over $\mathrm{MgSO}_{4}$ and evaporated to dryness under reduced pressure. Column chromatography $\left(\mathrm{CH}_{2} \mathrm{Cl}_{2} / \mathrm{MeOH} 97: 3 ; R_{\mathrm{f}}=0.5\right.$ with $\left.\mathrm{CH}_{2} \mathrm{Cl}_{2} / \mathrm{MeOH} 94: 6\right)$ yielded $15(138 \mathrm{mg}, 39 \%)$ as a pale brown solid. $[\alpha]^{20}{ }_{\mathrm{D}}=-11.6\left(\mathrm{c}=1\right.$ in $\left.\mathrm{MeOH} / \mathrm{CH}_{2} \mathrm{Cl}_{2}\right)$; IR: $v 3347(\mathrm{~m}), 2935(\mathrm{~m}), 2498(\mathrm{~m}), 1710$ (s), 1659 (s), 1435 (s), 1207 (s), 1154 (s), 991 (m), 887 (m), 787 (m), 729 (m); ${ }^{1} \mathrm{H}$ NMR (400 MHz, $\mathrm{CDCl}_{3} / \mathrm{MeOD}$ 6:1): $\delta 8.62(\mathrm{~s}, 2 \mathrm{H}), 5.92(\mathrm{brs}, 1 \mathrm{H}), 5.70-5.57(\mathrm{~m}, 1 \mathrm{H}), 5.56-5.51(\mathrm{~m}, 1 \mathrm{H}), 5.11-$ $4.95(\mathrm{~m}, 2 \mathrm{H}), 4.29-4.21(\mathrm{~m}, 4 \mathrm{H}), 3.49-3.41(\mathrm{~m}, 2 \mathrm{H}), 2.50-2.40(\mathrm{~m}, 1 \mathrm{H}), 2.40-2.30(\mathrm{~m}, 1 \mathrm{H})$, 2.27 - $2.17(\mathrm{~m}, 2 \mathrm{H}), 1.20(\mathrm{~s}, 9 \mathrm{H}) ;{ }^{13} \mathrm{C} \mathrm{NMR}\left(125 \mathrm{MHz}, \mathrm{CDCl}_{3} / \mathrm{MeOD} 6: 1\right): \delta$ 175.7(s), 175.2(s), 164.8(s), 164.6(s), 164.3(s), 164.0(s), 160.6(s), 143.5(s), 143.4(s), 139.3(d), 139.1(s), 136.1(d), 130.8(s), 130.6(s), 129.4(s), 129.3(s), 125.8(s), 125.7(s), 120.6(t), 69.3(s), 68.8(t), 57.9(d), 44.3(t), 42.4(t), 35.8(t), 26.7(q), 18.3(t); MS (ESI, +ve): $m / z(\%) 647\left(15[\mathrm{M}+\mathrm{H}]^{+}\right), 591\left(100\left[\mathrm{M}-\mathrm{C}_{4} \mathrm{H}_{9}+\right.\right.$ $\left.\mathrm{H}]^{+}\right), 574\left(90\left[\mathrm{M}-\mathrm{C}_{4} \mathrm{H}_{9}-\mathrm{OH}\right]^{+}\right)$.

Alloc-en- $N, N$-NDI-Glu(tert-Bu)- $\mathbf{N H}_{2}$ 16. A sealed tube was charged with a solution of $\mathbf{1 5}$ (50 $\mathrm{mg}, 0.077 \mathrm{mmol})$ in isopropylamine $(0.5 \mathrm{ml})$ to which was added $\mathrm{N}, \mathrm{N}^{\prime}$-dimethylimidazolidinone (1 $\mathrm{ml}){ }^{\mathrm{S} 7}$ The tube was sealed and the stirred reaction mixture was heated at $60{ }^{\circ} \mathrm{C}$ for $20 \mathrm{~h}$. During this time the red solution changed to a purple color. This solution was diluted with EtOAc (50 ml) and washed with brine $(5 \times 100 \mathrm{ml})$. The organic phase was dried over $\mathrm{MgSO}_{4}$ and evaporated to dryness under reduced pressure. Column chromatography $\left(\mathrm{CH}_{2} \mathrm{Cl}_{2} / \mathrm{MeOH} 97: 2 ; R_{\mathrm{f}}=0.5\right.$ with $\left.\mathrm{CH}_{2} \mathrm{Cl}_{2} / \mathrm{MeOH} 94: 6\right)$ yielded $16(32 \mathrm{mg}, 60 \%)$ as a blue solid. $[\alpha]^{20}{ }_{\mathrm{D}}=-13.2(\mathrm{c}=1 \mathrm{in}$ 
$\mathrm{MeOH} / \mathrm{CH}_{2} \mathrm{Cl}_{2}$ ); IR: v 3333 (m), 2923 (m), 2852 (m), 1695 (s), 1631 (s), 1583 (s), 1486 (s), 1258

(s), 1154 (s), 1089 (m), 1016 (m), 791 (s); ${ }^{1} \mathrm{H}$ NMR (400 MHz, $\left.\mathrm{CDCl}_{3}\right): \delta 9.28\left(\mathrm{~d},{ }^{3} J(\mathrm{H}, \mathrm{H})=7.6\right.$ $\mathrm{Hz}, 1 \mathrm{H}), 9.21\left(\mathrm{~d},{ }^{3} J(\mathrm{H}, \mathrm{H})=8.0 \mathrm{~Hz}, 1 \mathrm{H}\right), 8.14(\mathrm{~s}, 1 \mathrm{H}), 8.08(\mathrm{~s}, 1 \mathrm{H}), 5.92-5.82(\mathrm{~m}, 1 \mathrm{H}), 5.81-$ $5.78(\mathrm{~m}, 1 \mathrm{H}), 5.45-5.13(\mathrm{~m}, 2 \mathrm{H}), 4.56(\mathrm{bs}, 2 \mathrm{H}), 4.32-4.28(\mathrm{~m}, 2 \mathrm{H}), 4.17-4.02(\mathrm{~m}, 2 \mathrm{H}), 3.61-$ $3.51(\mathrm{~m}, 2 \mathrm{H}), 2.77-2.65(\mathrm{~m}, 1 \mathrm{H}), 2.59-2.49(\mathrm{~m}, 1 \mathrm{H}), 2.49-2.31(\mathrm{~m}, 2 \mathrm{H}), 1.44(\mathrm{bs}, 21 \mathrm{H}) ;{ }^{13} \mathrm{C}$ NMR (125 MHz, $\mathrm{CDCl}_{3} / \mathrm{MeOD}$ 6:1): $\delta$ 172.3(s), 171.9(s), 166.2(s), 165.8(s), 163.3(s), 163.2(s), 156.6(s), 148.6(s), 148.4(s), 133.1(d), 128.9(d), 128.3(d), 119.2(s), 119.2(s), 119.0(s), 119.0(s), 103.2(s), 101.4(s), 80.9(s), 65.8(t), 53.9(d), 44.5(d), 40.0(t), 39.6(t), 29.9(q), 24.1(t), 23.3(q), 23.3(q), 22.9(t); MS (ESI, +ve): $m / z(\%) 693\left(50[\mathrm{M}+\mathrm{H}]^{+}\right), 638\left(45\left[\mathrm{M}-\mathrm{C}_{4} \mathrm{H}_{9}+\mathrm{H}\right]^{+}\right), 620(100$ $\left.\left[\mathrm{M}-\mathrm{C}_{4} \mathrm{H}_{9}-\mathrm{OH}\right]^{+}\right)$; HR-MS (ESI, +ve): Calcd for $\mathrm{C}_{35} \mathrm{H}_{45} \mathrm{O}_{9} \mathrm{~N}_{6}{ }^{+}:$693.3242, Found: 693.3247.

H-en- $N, N$-NDI-Glu(tert-Bu)- $\mathbf{N H}_{2}$ 17. To a solution of 16 (35 mg, $\left.0.051 \mathrm{mmol}\right)$ in $\operatorname{dry} \mathrm{CH}_{2} \mathrm{Cl}_{2}$ (20 ml) were added $p$-nitrophenol $(21 \mathrm{mg}, 0.152 \mathrm{mmol})$ and tributyltin hydride $(74 \mathrm{mg}, 0.255 \mathrm{mmol})$ followed by $\mathrm{Pd}\left(\mathrm{PPh}_{3}\right)_{2} \mathrm{Cl}_{2}(4 \mathrm{mg}, 0.005 \mathrm{mmol})$. After stirring for $3 \mathrm{~h}$ the reaction mixture was dried under reduced pressure and lipophilic impurities were removed by solid-liquid extraction with petroleum ether $(5 \times 5 \mathrm{ml})$. Further purification by column chromatography $\left(\mathrm{CH}_{2} \mathrm{Cl}_{2} / \mathrm{MeOH} 90: 10\right.$ then $\mathrm{CH}_{2} \mathrm{Cl}_{2} / \mathrm{MeOH} / \mathrm{TEA}$ 90:10:1; $R_{\mathrm{f}}=0.4$ with $\mathrm{CH}_{2} \mathrm{Cl}_{2} / \mathrm{MeOH} / \mathrm{TEA}$ 90:10:1) gave amine 17 (28 mg, quantitative) as a blue solid. $[\alpha]^{20}{ }_{\mathrm{D}}=-10.2(\mathrm{c}=1 \mathrm{in} \mathrm{MeOH}) ;{ }^{1} \mathrm{H} \mathrm{NMR}\left(400 \mathrm{MHz}, \mathrm{CDCl}_{3}\right): \delta$ $9.30-9.28(\mathrm{~m}, 2 \mathrm{H}), 8.18(\mathrm{bs}, 2 \mathrm{H}), 5.75-5.69(\mathrm{~m}, 1 \mathrm{H}), 4.38-4.31(\mathrm{~m}, 2 \mathrm{H}), 4.11-4.08(\mathrm{~m}, 2 \mathrm{H})$, $3.24-3.17(\mathrm{~m}, 2 \mathrm{H}), 2.61-2.32(\mathrm{~m}, 2 \mathrm{H}), 2.30-2.20(\mathrm{~m}, 2 \mathrm{H}), 1.40-1.35(\mathrm{~m}, 12 \mathrm{H}), 1.31(\mathrm{~s}, 9 \mathrm{H})$; MS (ESI, +ve): $m / z(\%) 631\left(15[\mathrm{M}+\mathrm{Na}]^{+}\right), 609\left(65[\mathrm{M}+\mathrm{H}]^{+}\right), 592\left(100[\mathrm{M}-\mathrm{OH}]^{+}\right), 537(60[\mathrm{M}$ $\left.-\mathrm{C}_{4} \mathrm{H}_{9}-\mathrm{OH}\right]^{+}$. 


\section{$1^{4}$-(2- Lipoylaminoethoxy)-1 $1^{2}, 2^{2}, 3^{3}, 4^{2}$-tetra(Gla-en-N,N-NDI-Glu(tert-Bu)-NH$)$-p-}

quaterphenyl 19. A solution of quaterphenyl $13(5 \mathrm{mg}, 6 \mu \mathrm{mol})$ in $\mathrm{CH}_{2} \mathrm{Cl}_{2}(0.5 \mathrm{ml})$ and TFA $(0.5$ $\mathrm{ml}$ ) was stirred for $15 \mathrm{~min}$ at $\mathrm{rt}$, and then concentrated in vacuo to give tetra acid $\mathbf{1 8}$ (5 mg, quant). The obtained tetra acid was dissolved in DMF (0.5 ml), and HATU (18 mg, $47 \mu \mathrm{mol})$, di-tert-butyl pyridine (40 $\mu \mathrm{l}, 0.18 \mathrm{mmol}), 17(20 \mathrm{mg}, 33 \mu \mathrm{mol})$ and TEA (15 $\mu \mathrm{l}, 0.11 \mathrm{mmol})$ were successively added. After stirring for $0.5 \mathrm{~h}$ at $\mathrm{rt}$, the mixture was diluted by $\mathrm{CH}_{2} \mathrm{Cl}_{2}$, washed with $1 \mathrm{M} \mathrm{HCl}$ and brine, dried over $\mathrm{Na}_{2} \mathrm{SO}_{4}$ and concentrated in vacuo. Purification of the residue by PTLC $\left(\mathrm{CH}_{2} \mathrm{Cl}_{2} /\right.$ MeOH 9 / 1) and HPLC (YMC-pack-SIL, 10 x 250 mm, $\mathrm{CH}_{2} \mathrm{Cl}_{2} / \mathrm{MeOH} 9 / 1,2 \mathrm{ml} / \mathrm{min}, R_{\mathrm{t}}=6.8$ min) gave pure tetramer $19(4 \mathrm{mg}, 21 \%)$ as a blue amorphous solid. ${ }^{1} \mathrm{H}$ NMR $\left(300 \mathrm{MHz}, \mathrm{CDCl}_{3}\right): \delta$ $9.25 \sim 9.10(\mathrm{~m}, 6 \mathrm{H}), 9.05 \sim 8.90(\mathrm{~m}, 2 \mathrm{H}), 8.05 \sim 7.95(\mathrm{~m}, 4 \mathrm{H}), 7.86(\mathrm{~s}, 2 \mathrm{H}), 7.79(\mathrm{~s}, 2 \mathrm{H}), 7.60 \sim$ $7.20(\mathrm{~m}, 7 \mathrm{H}), 7.10 \sim 6.50(\mathrm{~m}, 5 \mathrm{H}), 6.28(\mathrm{brs}, 1 \mathrm{H}), 5.75 \sim 5.65$ (brs, $4 \mathrm{H}), 4.50 \sim 3.73(\mathrm{~m}, 26 \mathrm{H}), 3.73$ $\sim 3.05(\mathrm{~m}, 13 \mathrm{H}), 2.81 \sim 2.60(\mathrm{~m}, 4 \mathrm{H}), 2.53 \sim 2.19(\mathrm{~m}, 15 \mathrm{H}), 2.00 \sim 1.83(\mathrm{~m}, 1 \mathrm{H}), 1.80 \sim 1.60(\mathrm{~m}$, $4 \mathrm{H}), 1.41 \sim 1.26(\mathrm{~m}, 84 \mathrm{H})$.

\section{$1^{4}$-(2- Lipoylaminoethoxy)-12 $2^{2}, 3^{3}, 4^{2}$-tetra(Gla-en- $N, N$-NDI-Glu-NH $)$-p-quaterphenyl 1.} A solution of tetra-NDI $19(4 \mathrm{mg}, 1.2 \mu \mathrm{mol})$ in $\mathrm{CH}_{2} \mathrm{Cl}_{2}(0.5 \mathrm{ml})$ and TFA $(0.5 \mathrm{ml})$ was stirred for 15 min at rt, and then concentrated in vacuo to give HPLC pure (YMC ODS-A, 10 x $250 \mathrm{~mm}, \mathrm{MeOH} /$ TFA $\left.99 / 1,2 \mathrm{ml} / \mathrm{min}, R_{\mathrm{t}}=7.7 \mathrm{~min}\right)$ title compound $\left(1,4 \mathrm{mg}\right.$, quant) as a blue amorphous solid. ${ }^{1} \mathrm{H}$ NMR (300 MHz, $\left.\mathrm{CDCl}_{3}\right): \delta 7.90 \sim 7.73(\mathrm{~m}, 6 \mathrm{H}), 7.68(\mathrm{~s}, 2 \mathrm{H}), 7.40 \sim 7.13(\mathrm{~m}, 8 \mathrm{H}), 7.03 \sim 6.95(\mathrm{~m}$, 2H), $6.76(\mathrm{~m}, 1 \mathrm{H}), 6.55(\mathrm{~m}, 1 \mathrm{H}), 6.40(\mathrm{brs}, 1 \mathrm{H}), 5.67 \sim 5.56(\mathrm{brs}, 4 \mathrm{H}), 4.42 \sim 3.70(\mathrm{~m}, 26 \mathrm{H}), 3.60 \sim$ $3.20(\mathrm{~m}, 13 \mathrm{H}), 2.72 \sim 2.55(\mathrm{~m}, 5 \mathrm{H}), 2.46 \sim 2.13(\mathrm{~m}, 16 \mathrm{H}), 1.88 \sim 1.72(\mathrm{~m}, 1 \mathrm{H}), 1.68 \sim 1.50(\mathrm{~m}, 4 \mathrm{H})$, 
1.26 (brs, 12H), 1.24 (brs, 36H); MS (ESI, -ve): $m / z(\%) 1501.3\left(100[\mathrm{M}-3 \mathrm{H}+\mathrm{Na}]^{2-}\right)$.

\subsection{Synthesis of the cationic propagator 2}

Compound 2 was prepared following previously reported procedures. ${ }^{\mathrm{S} 1}$

\subsection{Synthesis of the anionic propagator 3}

$1^{3}, 2^{3}, 3^{2}, 4^{3}, 5^{2}, 6^{3}, 7^{2}, 8^{3}$-Octakis(Gla-OH)-p-octiphenyl 20. This compound was prepared from Fast Blue B in overall nine steps following previously reported procedures. ${ }^{\mathrm{S} 8}$

$1^{3}, 2^{3}, 3^{2}, 4^{3}, 5^{2}, 6^{3}, 7^{2}, 8^{3}$-Octakis(Gla-en-N,N-NDI-Glu(tert-Bu)-NH$)$-p-octiphenyl 21. A solution of $p$-octiphenyl 20 (5 mg, $0.0042 \mathrm{mmol})$, HATU (19 mg, $0.050 \mathrm{mmol}$ ) and 2,6,di-tertbutylpyridine $(76 \mathrm{mg}, 0.40 \mathrm{mmol})$ in dry DMF (1 ml) was stirred for $30 \mathrm{~min}$. Then a solution of $\mathbf{1 7}$ (30 mg, $0.050 \mathrm{mmol})$ and TEA (27 mg, $0.266 \mathrm{mmol})$ in dry DMF (2 ml) was added and after stirring for $16 \mathrm{~h}$ the reaction mixture was evaporated to dryness azeotropically with toluene. A preliminary purification by column chromatography $\left(\mathrm{CH}_{2} \mathrm{Cl}_{2} / \mathrm{MeOH} 90: 10\right)$ was followed by two PTLCs (first $\mathrm{CH}_{2} \mathrm{Cl}_{2} / \mathrm{MeOH} 94: 6, R_{\mathrm{f}}=0.3$, then $\left.\mathrm{CH}_{2} \mathrm{Cl}_{2} / \mathrm{MeOH} 85: 15, R_{\mathrm{f}}=0.9\right)$ to give $21(15 \mathrm{mg}, 60 \%)$ as a blue solid. HPLC: YMC-Pack SIL $250 \times 4.6 \mathrm{~mm}, \mathrm{CH}_{2} \mathrm{Cl}_{2} / \mathrm{MeOH} 93: 7,2 \mathrm{ml} / \mathrm{min}, R_{\mathrm{t}}=6.9 \mathrm{~min} . ;{ }^{1} \mathrm{H}$ NMR (400 MHz, $\left.\mathrm{CDCl}_{3} / \mathrm{CD}_{3} \mathrm{OD} 1: 1\right): \delta 9.14-8.76$ (m, 16H), 8.02 - 7.55 (m, 16H), $7.44-6.91$ $(\mathrm{m}, 24 \mathrm{H}), 6.73-6.68(\mathrm{~m}, 2 \mathrm{H}), 5.61-5.42(\mathrm{~m}, 8 \mathrm{H}), 4.40-4.11(\mathrm{~m}, 16 \mathrm{H}), 4.09-3.85(\mathrm{~m}, 16 \mathrm{H})$ $3.81-3.55(\mathrm{~m}, 16 \mathrm{H}), 3.45-3.12(\mathrm{~m}, 16 \mathrm{H}), 2.57-2.41(\mathrm{~m}, 8 \mathrm{H}), 2.31-2.05(\mathrm{~m}, 24 \mathrm{H}), 1.44-1.05$ 
(m, 168H); MS (MALDI, +ve linear, dithranol): $m / z(\%) 5947\left(100[\mathrm{M}+\mathrm{Na}]^{+}\right), 5925(70[\mathrm{M}+$ $\left.\mathrm{H}]^{+}\right)$.

$1^{3}, 2^{3}, 3^{2}, 4^{3}, 5^{2}, 6^{3}, 7^{2}, 8^{3}$-Octakis(Gla-en- $N, N$-NDI-Glu-NH $)$-p-octiphenyl 3. A solution of 21 (7 mg, $1.2 \mu \mathrm{mol})$ in TFA $(1 \mathrm{ml})$ and $\mathrm{CH}_{2} \mathrm{Cl}_{2}(1 \mathrm{ml})$ was stirred for $1 \mathrm{~h}$. After this time the red solution was evaporated to dryness under reduced pressure. Impurities were removed by solidliquid extraction with petroleum ether $(3 \times 2 \mathrm{ml})$ leaving $3(6.4 \mathrm{mg}$, quantitative $)$ as a blue solid. ${ }^{1} \mathrm{H}$ NMR (400 MHz, DMSO-d6): $\delta 9.20-8.89(\mathrm{~m}, 16 \mathrm{H}), 8.02-7.10(\mathrm{~m}, 42 \mathrm{H}), 5.48-5.23(\mathrm{~m}, 8 \mathrm{H})$, $4.61-4.29(\mathrm{~m}, 16 \mathrm{H}), 4.31-3.62(\mathrm{~m}, 32 \mathrm{H}), 3.47-3.10(\mathrm{~m}, 16 \mathrm{H}), 2.69-2.35(\mathrm{~m}, 16 \mathrm{H}), 2.31-$ $2.01(\mathrm{~m}, 16 \mathrm{H}), 1.40$ - $0.95(\mathrm{~m}, 96 \mathrm{H})$; MS (MALDI, +ve linear, dithranol): $\mathrm{m} / z(\%) 5523(50[\mathrm{M}+$ $\left.2 \mathrm{Na}-\mathrm{H}]^{+}\right), 5500\left(100[\mathrm{M}+\mathrm{Na}]^{+}\right), 5478\left(60[\mathrm{M}+\mathrm{H}]^{+}\right)$.

\subsection{Electrochemistry}

Oxidation and reduction potentials of $\mathbf{1 6}$ and $1^{3}, 2^{3}, 3^{2}, 4^{3}-p$-quateranisole $\mathbf{2 2}^{\mathrm{S} 8}$ were determined by cyclic voltammetry vs $\mathrm{Fc} / \mathrm{Fc}^{+}$in dichloromethane (scan rate $100 \mathrm{mV} / \mathrm{s}$, supporting electrolyte: $100 \mathrm{mM} \mathrm{Bu}_{4} \mathrm{NPF}_{6}$, working electrode: Pt disk, counter electrode: Pt wire, reference electrode: $\mathrm{Ag} / \mathrm{AgCl})$. Results are shown in Table $\mathrm{S} 1$ in comparison with literature data for related NDI 4, $p$ quaterphenyl (23) and $p$-octiphenyl (24). ${ }^{\mathrm{S} 9}$ HOMO and LUMO energies were calculated from oxidation and reduction potentials using eq $[\mathrm{S} 1]^{\mathrm{S} 10}$

$$
E_{\mathrm{HOMO} / \mathrm{LUMO}}=-4.8 \mathrm{eV}-E_{1 / 2} \mathrm{Vs}\left(\mathrm{Fc} / \mathrm{Fc}^{+}\right)
$$


The obtained bandgaps $E_{\mathrm{LUMO}}-E_{\mathrm{HOMO}}$ were converted into absorption wavelength using eq [S2]

$$
\lambda_{\text {calc }}(\mathrm{nm})=h c /\left(E_{\mathrm{LUMO}}-E_{\mathrm{HOMO}}\right)=1240 /\left(E_{\mathrm{LUMO}}-E_{\mathrm{HOMO}}\right)
$$

and compared to the measured values $\lambda_{\max }$ (Tab. S1, Fig. S4).

\subsection{Zipper assembly on gold nanoparticles (Au-nps)}

Preparation of Au-nps. Au-nps were prepared following the reported procedures. ${ }^{\text {S11 }}$ Namely, to a boiling aqueous solution of $\mathrm{HAuCl}_{4}(5 \mathrm{mg}$ in $25 \mathrm{ml})$ was added $1 \%$ sodium citrate aqueous solution $(2.5 \mathrm{ml})$. After $10 \mathrm{~min}$ of boiling, the mixture was cooled to give wine red dispersion of citrate-stabilized Au-nps. The absorbance as well as the absorption maximum were in agreement with the reported values for $\sim 17 \mathrm{nM}$ Au-nps with $13 \mathrm{~nm}$ diameters. ${ }^{\text {S11 }}$ The suspension was centrifuged (14,500 rpm for $30 \mathrm{~min})$ and the supernatant removed to give the concentrated Aunps $(100 \mathrm{nM})$.

Initiation. Au-nps $(50 \mathrm{nM})$ were suspended in the solution of the initiator $\mathbf{1}(24 \mu \mathrm{M})$ in TFE- $0.01 \%$ sodium citrate aqueous solution $(1: 1)$. The mixture was shaken overnight and then centrifuged. The resulting pellet was suspended in the mixture of TFE-water (1:1) with the aid of bath sonicator and centrifuged again. The precipitate was suspended in sodium phosphate buffer (1 
$\mathrm{mM}, \mathrm{pH}$ 7.4) to obtain its UV-vis absorption spectrum. The resulting particles were insensitive to ionic strength (Fig. S4A). Surface coverage of 1 on Au-nps was estimated to be about $0.23 \mathrm{nmol} /$ $\mathrm{cm}^{2}$ from the absorbance at $630 \mathrm{~nm}$ relative to that of SPR band of Au-nps. This value is in good agreement with the literature values: $\leq 0.75 \mathrm{nmol} / \mathrm{cm}^{2}$ of alkanethiols on gold $^{\mathrm{S} 12} ; \leq 56 \mathrm{pmol} / \mathrm{cm}^{2}$ of DNA on Au-nps. ${ }^{\text {S13 }}$

Propagation. Au-1-nps (24 nM) were suspended in the solution of cationic propagator 2 (10 $\mu \mathrm{M})$ in sodium phosphate buffer $(1 \mathrm{mM}, \mathrm{pH} 7.4)$ and shaken for $0.5 \mathrm{~h}$. Then the particles were centrifuged down, re-suspended in the same buffer, and centrifuged again to give the particles with two coating layers as a precipitate. The following layers were formed similarly by depositing alternately charged propagators ( $\mathbf{3}$ and $\mathbf{2}$ ), and purified by centrifugal separation. UV-vis spectra were obtained after each deposition of the layers (Figs. 2 and S4B). Control experiments showed the reproducible formation of multi-layers independent of the concentration of coated Au-nps (between $\sim 0.3$ to $30 \mathrm{nM}$ ).

Termination (Fig. 2B). Au-1-2-nps with two coating layers $(\sim 1 \mathrm{nM})$ were shaken for $0.5 \mathrm{~h}$ in a mixture of TFE/ $\mathrm{H}_{2} \mathrm{O}(1: 1)$ containing terminator $\mathbf{1}(0.7 \mu \mathrm{M})$. After centrifugation and rinsing with $\mathrm{TFE} / \mathrm{H}_{2} \mathrm{O}(1: 1)$, the obtained precipitate was suspended in sodium phosphate buffer $(1 \mathrm{mM}$, $\mathrm{pH}$ 7.4) containing cationic propagator $2(0.5 \mu \mathrm{M})$. After $0.5 \mathrm{~h}$ of shaking, the mixture was centrifuged and the precipitate was rinsed with buffer. Absorption spectra of a suspension in $1: 1$ TFE $/ \mathrm{H}_{2} \mathrm{O}$ were recorded. Note, capped Au-1-2-1-nps undergo aggregation if left overnight, probably caused by cross-linking of nps via formation of new Au-S bonds with terminator $\mathbf{1}$. 


\subsection{Zipper assembly on gold electrodes}

Gold electrodes. Gold-coated glass slides $\left(22\right.$ x $\left.22 \mathrm{~mm}^{2}\right)$ were purchased from Mivitec $\mathrm{GmbH}$, Analytical $\mu$-Systems (Germany). Before use, the plates were cleaned using 'piranha' solution $\left(\mathrm{H}_{2} \mathrm{SO}_{4} / 30 \% \mathrm{H}_{2} \mathrm{O}_{2} 3 / 1 ; 35{ }^{\circ} \mathrm{C}\right.$ for $\left.5 \mathrm{~min}\right) .{ }^{\mathrm{S} 14}$ Caution: piranha solution reacts violently with organic compounds. It should be handled with extreme care. After the treatment with piranha solution, the plates were thoroughly rinsed with water and $\mathrm{EtOH}$, and used immediately.

Initiation. The cleaned gold plates were immersed in the solution of the initiator $1(\sim 7 \mu \mathrm{M})$ in

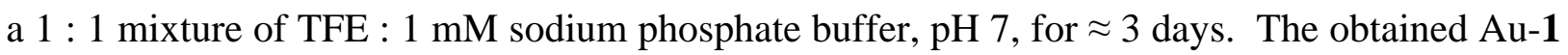
electrodes were tested for defects using the standard procedure in which reduction-oxidation of $\mathrm{K}_{3} \mathrm{Fe}(\mathrm{CN})_{6}\left(2 \mathrm{mM}\right.$ in $1 \mathrm{M}$ aqueous $\left.\mathrm{KNO}_{3}\right)$ was measured by cyclic voltammetry using coated gold plate as a working electrode (Fig. S5). ${ }^{\text {S15 }}$ The absence of redox wave confirmed the absence of large uncoated areas.

Propagation (Fig. 3). The initiated Au-1 electrodes were immersed in the solution of cationic propagator $2(\sim 10 \mu \mathrm{M})$ in a $1: 1$ mixture of TFE and $0.5 \mathrm{mM}$ sodium phosphate, $0.5 \mathrm{M} \mathrm{NaCl}$ buffer, $\mathrm{pH} 7$, for overnight. The plate was rinsed with bidistilled water and $\mathrm{EtOH}$, and the photocurrent of the resulting plate was recorded (see below). Obtained Au-1-2 electrodes were similarly treated with anionic propagator 3 to give Au-1-2-3 electrodes. The same sequences were repeated using alternately charged propagators ( $\mathbf{2}$ and $\mathbf{3})$ to build up the zipper. 
Mixed multilayers (Fig. 3B). Mixed multi-layers were built by using poly-L-Lysine (DP $\approx$ $134,0.1 \mu \mathrm{M}$ in $0.5 \mathrm{mM}$ sodium phosphate, $0.5 \mathrm{M} \mathrm{NaCl}$ buffer, $\mathrm{pH}$ 7) in place of cationic propagator $\mathbf{2}$ in the procedures described above.

Photocurrent measurements. The coated gold electrodes obtained by zipper assembly were used as a working electrode (Pt wire as a counter electrode) in an aqueous solution of TEOA (50 $\mathrm{mM})$ and $\mathrm{Na}_{2} \mathrm{SO}_{4}(0.1 \mathrm{M})$ and irradiated with a $150 \mathrm{~W}$ Xe lamp (Hamamatsu) through water to filter off IR component (area of irradiation $\sim 0.8 \mathrm{~cm}^{2}$ ). Changes in current upon on-off switching of irradiations (20 seconds each) were measured at $+0.4 \mathrm{~V}$ vs $\mathrm{Ag} / \mathrm{AgCl}$ unless stated. The power of irradiation was $\sim 1 \mathrm{~W} \mathrm{~cm}^{-2}$. For each gold plate, photocurrent obtained for $\mathrm{Au}-\mathbf{1}(0.5$ to $1.1 \mu \mathrm{A})$ was used as a standard (=1) and relative increase in current was reported for the following multi-layers (Fig. 3B).

Termination (Fig. 3). Au-1-2 electrodes were immersed in the solution of terminator $1(\sim 10$ $\mu \mathrm{M})$ in a $1: 1$ mixture of TFE and $0.5 \mathrm{mM}$ sodium phosphate, $0.5 \mathrm{M} \mathrm{NaCl}$ buffer $(\mathrm{pH} 7)$ for overnight. After successive rinsing with TFE and water, the obtained terminated Au-1-2-1 electrodes were treated repeatedly with cationic propagator $\mathbf{2}$, and then with anionic propagator $\mathbf{3}$ as described in the above "Propagation" section. Photocurrent measurements were performed as described above, but with a solar simulator (Oriel, $150 \mathrm{~W}$, with AM 1.5 filter). The power of irradiation was $0.55 \mathrm{Wcm}^{-2}$. Due to the different irradiation conditions, the observed photocurrents were systematically lower than the previously obtained values. To facilitate the comparison, on Fig. 
3A the photocurrents obtained under the irradiation with solar simulator were normalized to give the same currents for $\mathrm{Au}-\mathbf{1}$ under two different conditions.

\section{Supplementary schemes and figures}

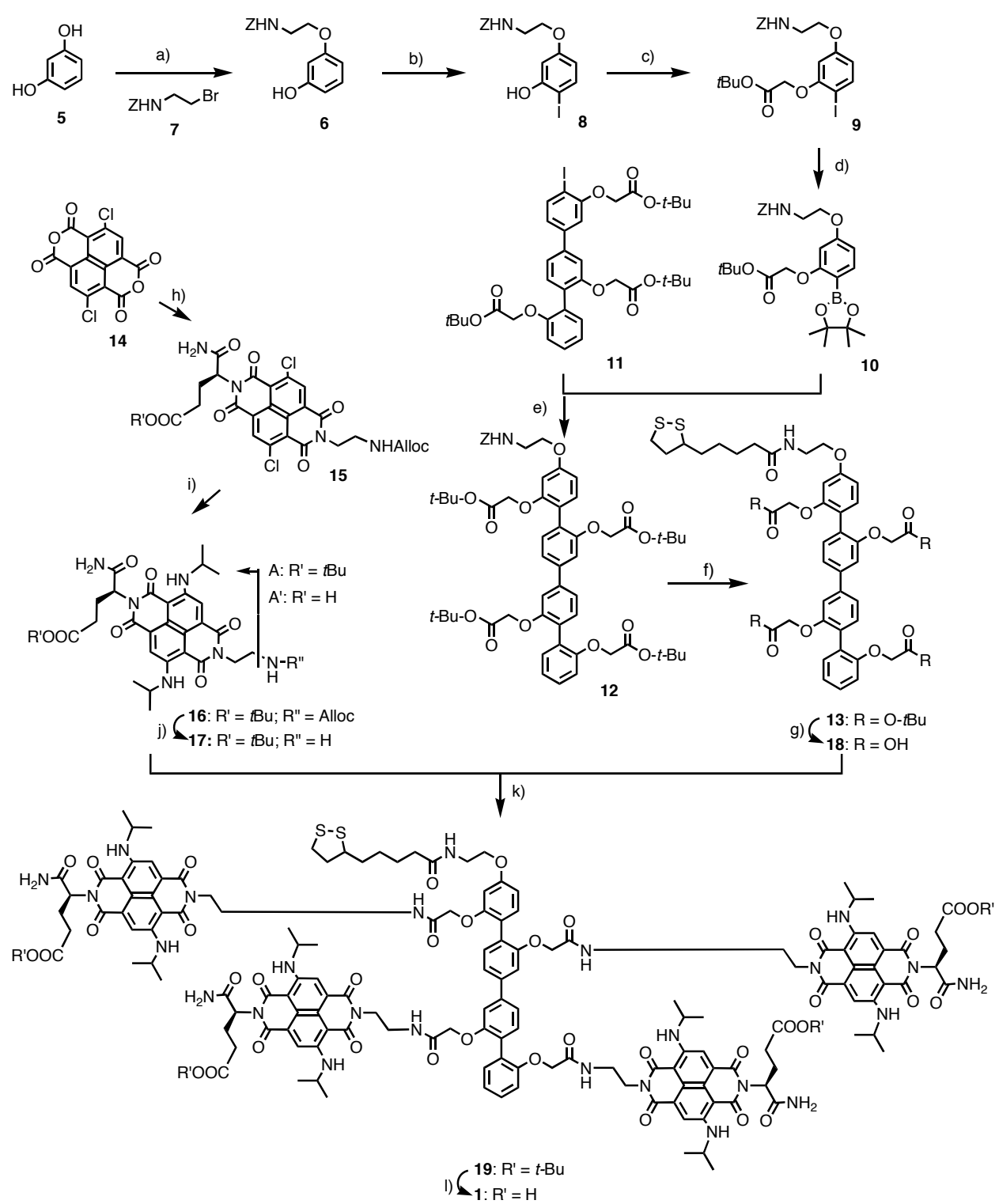

Scheme S1. a) 7, $\mathrm{Cs}_{2} \mathrm{CO}_{3}, \mathrm{DMF}, 40{ }^{\circ} \mathrm{C}(56 \%)$; b) $\mathrm{I}_{2}, \mathrm{AgOTf}, \mathrm{CHCl}_{3}$ (47 \%; conversion yield quant); c) $\mathrm{BrCH}_{2} \mathrm{COO}-t$-Bu, $\mathrm{Cs}_{2} \mathrm{CO}_{3}$, DMF, $90{ }^{\circ} \mathrm{C}$ (83 \%); d) $\mathrm{PdCl}_{2}$ (dppf), pinacolborane, TEA, $\mathrm{CH}_{3} \mathrm{CN}\left(87 \%\right.$ ); e) $\mathrm{PdCl}_{2}$ (dppf), $\mathrm{Na}_{2} \mathrm{CO}_{3}$, Toluene-EtOH (79\%); f) 1. $\mathrm{H}_{2}, \mathrm{Pd}-\mathrm{C}(79 \%)$; 2. lipoic acid, HATU, TEA, DMF (82 \%); g) TFA, $\mathrm{CH}_{2} \mathrm{Cl}_{2}$ (quant); h) Alloc-ethylenediamine, H-Glu(t-Bu)$\mathrm{NH}_{2}, \mathrm{AcOH}(39 \%)$; i) $i$ - $\mathrm{PrNH}_{2}(60 \%)$; j) $\mathrm{PdCl}_{2}\left(\mathrm{PPh}_{3}\right)_{2}, \mathrm{Bu}_{3} \mathrm{SnH}, p-\mathrm{NO}_{2}$-phenol (quant); k) 17, HATU, di- $t$-Bu-pyridine, TEA, DMF (21\%); 1) TFA, $\mathrm{CH}_{2} \mathrm{Cl}_{2}$ (quant). 

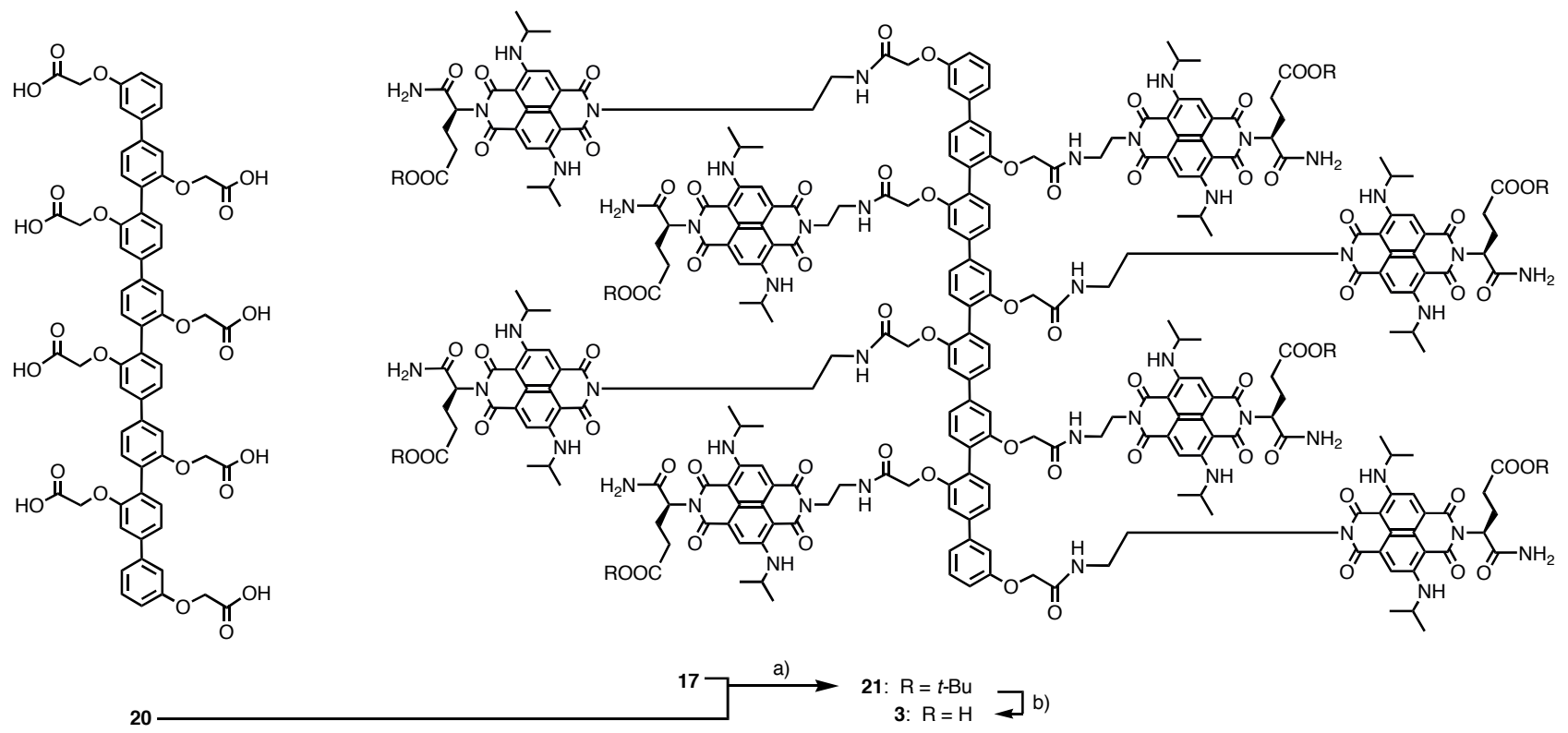

Scheme S2. a) HATU, di-t-Bu-pyridine, TEA, DMF (60\%); b) TFA, $\mathrm{CH}_{2} \mathrm{Cl}_{2}$ (quant). 

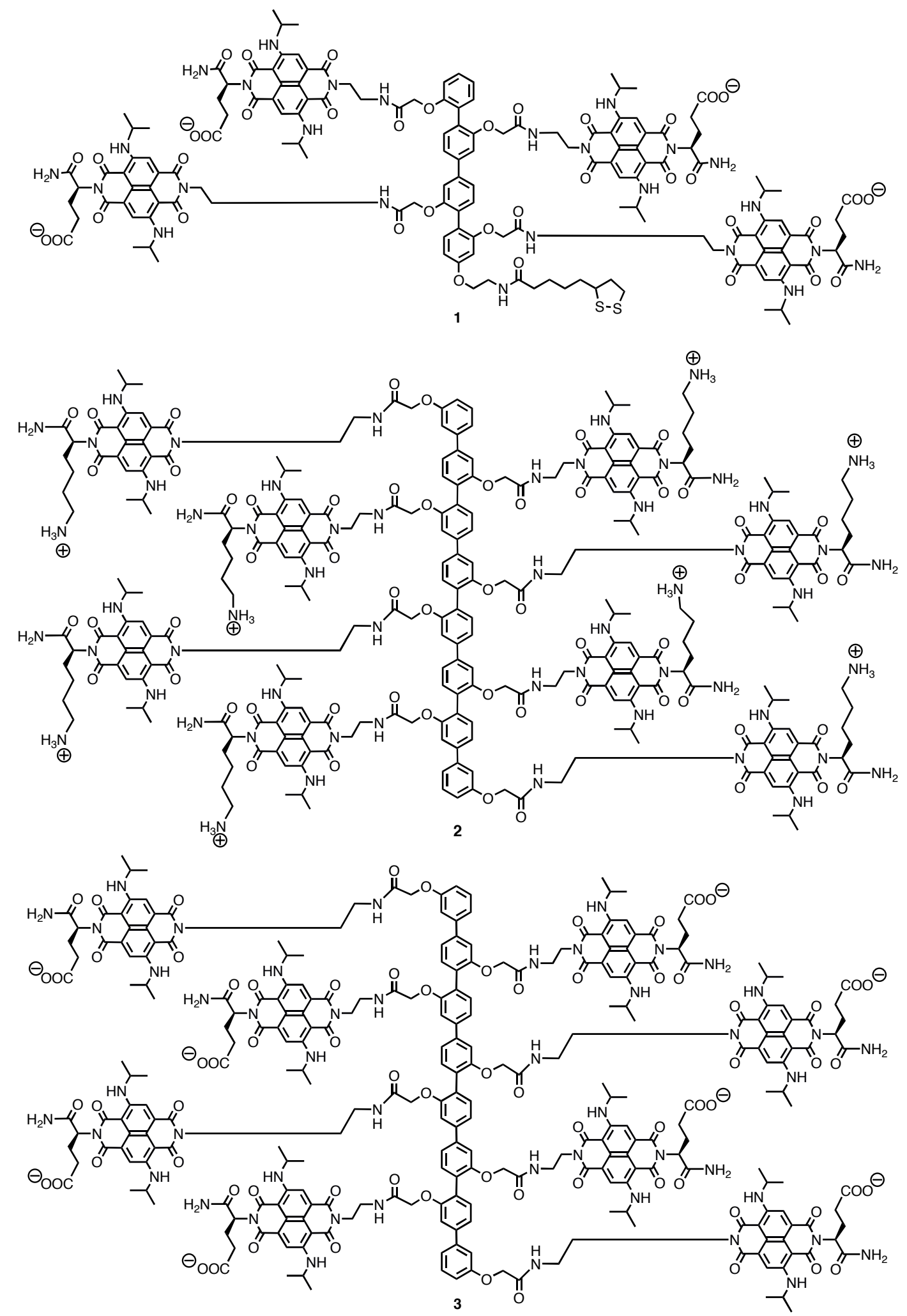

Fig S1. Complete structure of monomers 1-3 used for zipper assembly. 

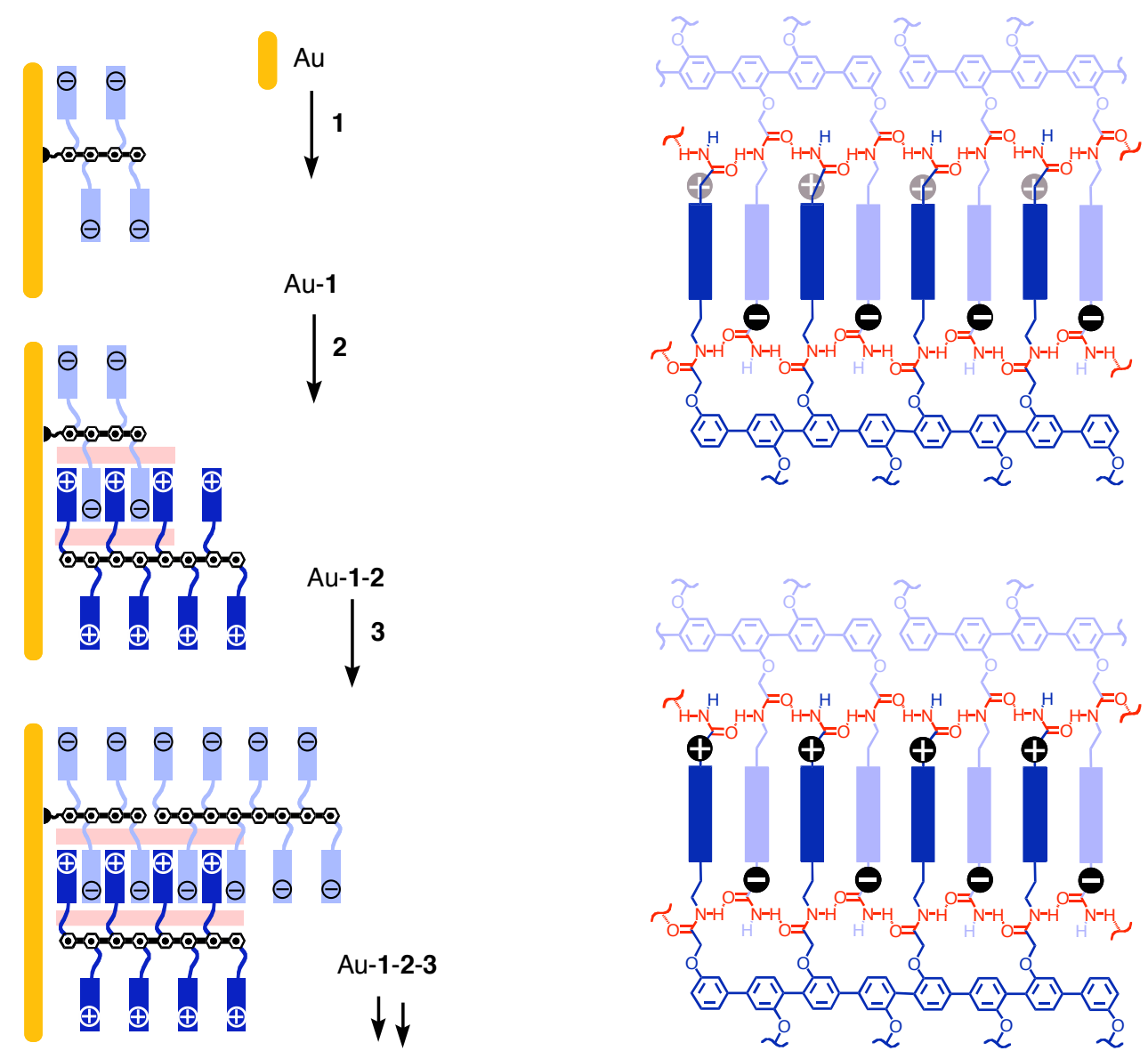

Fig S2. Expected suprastructure of the zipper (side view). Hydrogen-bonded chains (red) are introduced on both sides to orient the NDI $\pi$-stacks in zipper assembly (see refs (S1) and (S16) for molecular models). The antiparallel orientation of the resulting amide macrodipoles is arbitrary (but likely), as is the location of negative and positive charges on the same side (cis, bottom right) or on opposite sides of the stack (trans, top right, see Fig. S3). Charges behind stacks are shaded. 

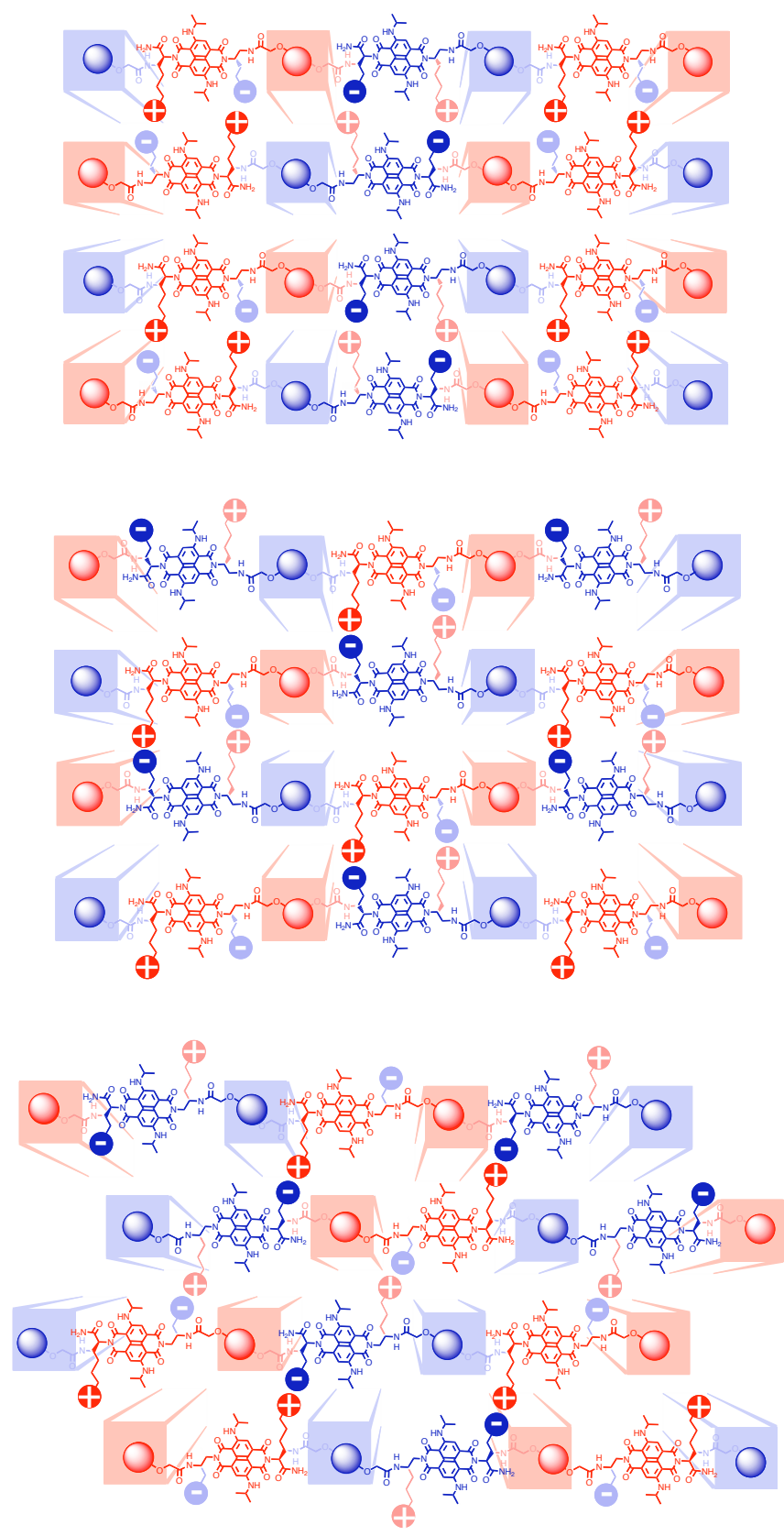

Fig S3. Expected suprastructure of the zipper (top view). Ion pairing between adjacent $\pi$-stacks is expected to assure, together with hydrophobic interactions, the higher-order (3D) organization of the zipper (Ion pairing is not possible within one $\pi$-stack because the charges are too far apart, compare also Fig. S2). The shown arrangements (rods as shaded circles) are arbitrary extremes out of many possibilities. Top: cis (charges on the same side of one stack) cisoid (charges on the same side across the rod); middle: cis-transoid; bottom: trans-transoid (bottom). 

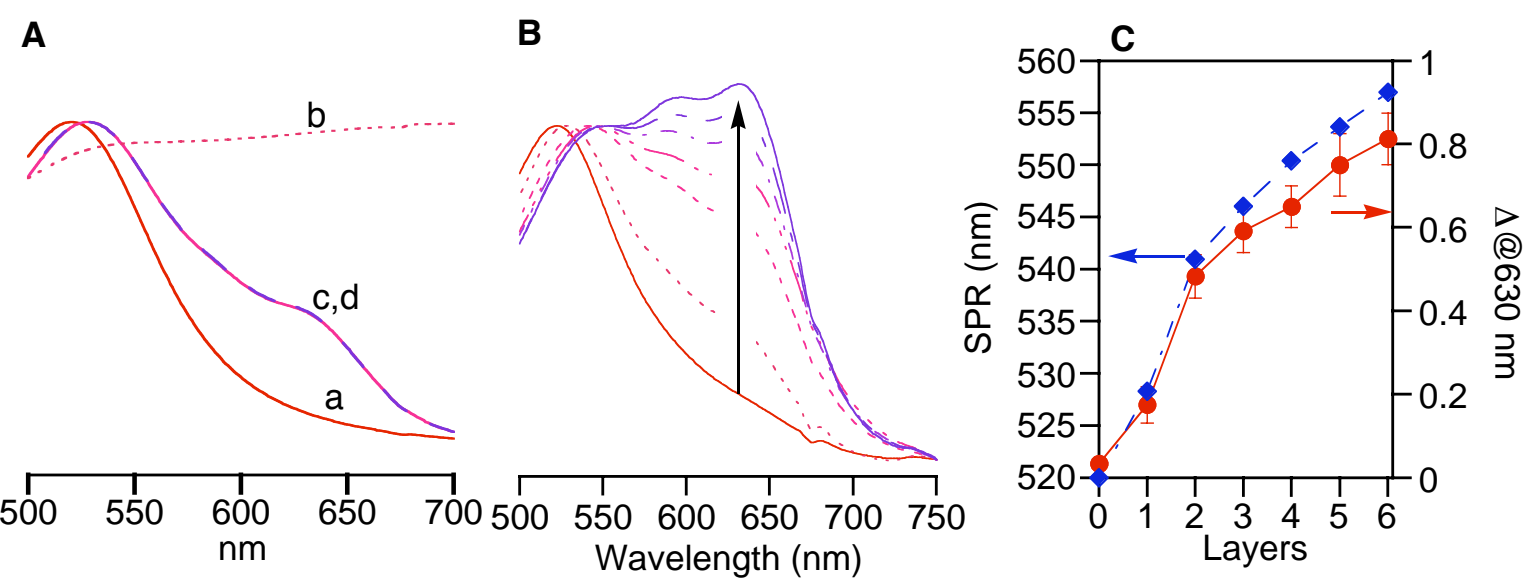

Fig S4. A. UV-vis spectra of Au-nps with / without SAM upon exposure to high ionic strength. a) citrate stabilized Au-nps; b) + 0.1 M NaCl; c) SAM coated Au-nps; d) + 0.1 M NaCl. B. UV-vis spectra of Au-nps with increasing number of layers. Spectra were normalized at $750 \mathrm{~nm}$ (as 0) and the peak of surface plasmon band (as 1). C. Correlation of SPR peaks (blue diamonds) and change in absorbance of NDIs at $630 \mathrm{~nm}$ relative to surface plasmon band (red circles) to the number of layers.

Comments for Fig. S4: Bathochromic shifts of SPR peaks by increasing number of layers could be attributed to the change in refractive index of the surroundings. ${ }^{\text {S17 }}$ 


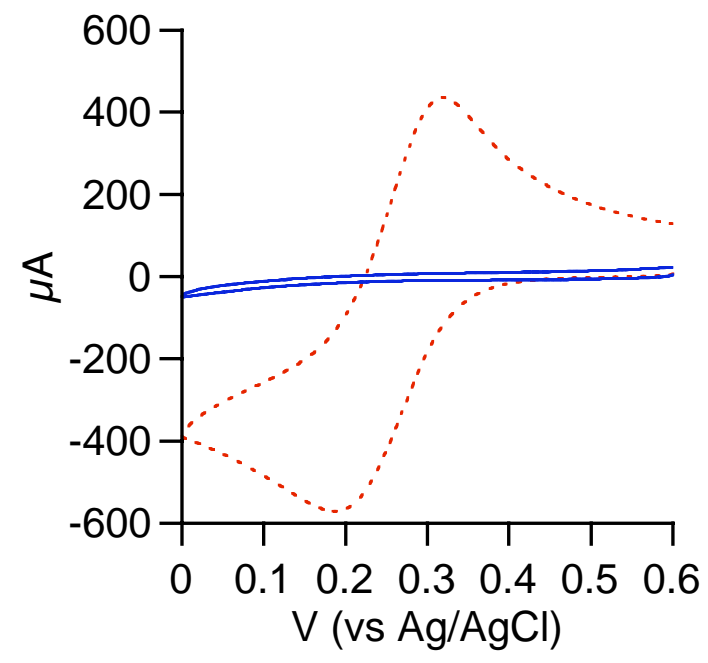

Fig. S5. Cyclic voltammogram of aqueous $\mathrm{K}_{3} \mathrm{Fe}(\mathrm{CN})_{6}$ using a gold plate with / without initiator $\mathbf{1}$ as a working electrode. Red dotted line: without $\mathbf{1}$; Blue solid line: with $\mathbf{1 .}$ 


\section{Supplementary tables}

Table S1 Electrochemical and spectroscopic data

\begin{tabular}{|c|c|c|c|c|c|}
\hline Dye & $\begin{array}{l}E_{1 / 2}\left(\mathrm{X} / \mathrm{X}^{+}\right) \\
\mathrm{V} \text { vs } \mathrm{Fc} / \mathrm{Fc}^{+}\end{array}$ & $\begin{array}{l}E_{\mathrm{HOMO}} \\
\mathrm{eV}\end{array}$ & $\begin{array}{l}E_{1 / 2}\left(\mathrm{X} / \mathrm{X}^{-}\right) \\
\mathrm{V} \mathrm{vs} \\
\mathrm{Fc} / \mathrm{Fc}^{+}\end{array}$ & $\begin{array}{c}E_{\text {LUMO }} \\
\mathrm{eV}\end{array}$ & $\begin{array}{l}\lambda_{\text {abs }}\left(\lambda_{\text {calc }}\right) \\
\mathrm{nm}\end{array}$ \\
\hline 16 & +0.62 & -5.4 & -1.33 & -3.5 & $620(636)$ \\
\hline $4^{a}$ & +0.60 & -5.4 & -1.40 & -3.4 & $620(620)$ \\
\hline 22 & $+1.10^{b}$ & -5.9 & & & \\
\hline $\mathbf{2 3}^{c}$ & +0.98 & -5.8 & -2.77 & -2.1 & \\
\hline $24^{d}$ & +0.79 & -5.6 & -2.20 & -2.6 & \\
\hline
\end{tabular}

$\overline{{ }^{a} \text { from ref S6; }{ }^{b} \text { irreversible, } E_{\mathrm{PA}} \text { is listed; }{ }^{c} \text { from ref } \mathrm{S} 9 \text { and } E_{1 / 2}\left(\mathrm{Fc} / \mathrm{Fc}^{+}\right)=0.49 \mathrm{~V}(v \mathrm{Ag} / \mathrm{AgCl})}$;

${ }^{d}$ estimated using eqs 1 and 2 in ref S9 and $E_{1 / 2}\left(\mathrm{Fc} / \mathrm{Fc}^{+}\right)=0.49 \mathrm{~V}(v s \mathrm{Ag} / \mathrm{AgCl})$.

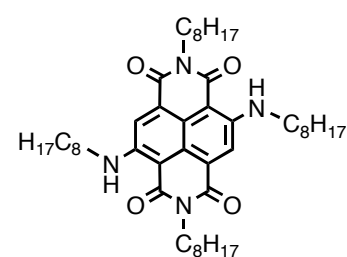

4

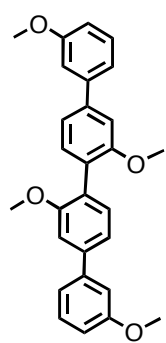

22

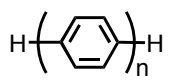

23: $n=4$

$24: n=8$ 


\section{Supplementary references}

S1. Bhosale, S.; Sisson, A. L.; Talukdar, P.; Fürstenberg, A.; Banerji, N.; Vauthey, E.; Bollot, G.; Mareda, J.; Röger, C.; Würthner, F.; Sakai, N.; Matile, S. Science 2006, 313, 84-86.

S2. Brouwer, A. J.; Liskamp, R. M. J. Eur. J. Org. Chem. 2005, 487-495.

S3. Tsukayama, M.; Utsumi, H.; Kunugi, A.; Nozaki, H. Heterocycles 1997, 45, 1131-1142.

S4. Murata, M.; Oyama, T.; Watanabe, S.; Masuda, Y. J. Org. Chem. 2000, 65, 164-168.

S5. Ronan, D.; Baudry, Y.; Jeannerat, D.; Matile, S. Org. Lett. 2004, 6, 885-887.

S6. Thalacker, C.; Röger, C.; Würthner, F. J. Org. Chem. 2006, 71, 8098-8105.

S7. Blaszczyk, A.; Fischer, M.; von Hänisch, C.; Mayor, M. Helv. Chim. Acta 2006, 89, 19862005

S8. Baumeister, B.; Sakai, N.; Matile, S. Org. Lett. 2001, 3, 4229.

S9. Meerholz, K.; Heinze, J. Electrochim. Acta 1996, 11/12, 1839.

S10. Yamamoto, Y.; Fukushima, T.; Suna, Y.; Ishii, N.; Saeki, A.; Seki, S.; Tagawa, S.; Taniguchi, M.; Kawai, T.; Aida, T. Science 2006, 314, 1761-1764.

S11. Keating, C. D.; Musick, M. D.; Keefe, M. H.; Natan, M. J. J. Chem. Ed. 1999, 76, 949-955.

S12. Love, J. C.; Estroff, L. A.; Kriebel, J. K.; Nuzzo, R. G.; Whitesides, G. M. Chem. Rev. 2005, 105, 1103-1169.

S13. Hurst, S. J.; Lytton-Jean, A. K. R.; Mirkin, C. A. Anal. Chem. 2006, 78, 8313-8318.

S14. Twardowski, M.; Nuzzo, R. Langmuir 2002, 18, 5529-5538.

S15. Porter, M. D.; Bright, T. B.; David, L.; Allara, D. L; Chidsey, C. E. D. J. Am. Chem. Soc. 
1987, 109, 3559-3568.

S16. Talukdar, P.; Bollot, G.; Mareda, J.; Sakai, N.; Matile, S. J. Am. Chem. Soc. 2005, 127, 65286529.

S17. a) Haes, A. J.; Zou, S.; Schatz, G. C.; Van Duyne, R. P. J. Phys. Chem. B 2004, 108, 109-116. b) Liu, G. L.; Yin, Y.; Kunchakarra, S.; Mukherjee, B.; Gerion, D.; Jett, S. D.; Bear, D. G.; Gray, J. W.; Alvisatos, A. P.; Lee, L. P.; Chen, F. F. Nat. Nanotech. 2006, 1, 47-52. 